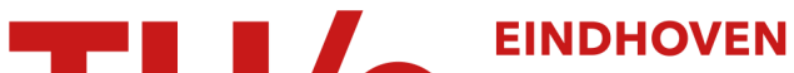 UNIVERSITY OF TECHNOLOGY
}

\section{Analysis of plasmonic waveguides : an embedding approach}

\author{
Citation for published version (APA): \\ Van Leuven, P. G., Van Beurden, M. C., \& Tijhuis, A. G. (2010). Analysis of plasmonic waveguides : an \\ embedding approach. In Proceedings - 2010 12th International Conference on Electromagnetics in Advanced \\ Applications, ICEAA'10 (pp. 489-490). [5653743] Institute of Electrical and Electronics Engineers. \\ https://doi.org/10.1109/ICEAA.2010.5653743
}

DOI:

10.1109/ICEAA.2010.5653743

Document status and date:

Published: 01/12/2010

\section{Document Version:}

Publisher's PDF, also known as Version of Record (includes final page, issue and volume numbers)

\section{Please check the document version of this publication:}

- A submitted manuscript is the version of the article upon submission and before peer-review. There can be important differences between the submitted version and the official published version of record. People interested in the research are advised to contact the author for the final version of the publication, or visit the $\mathrm{DOI}$ to the publisher's website.

- The final author version and the galley proof are versions of the publication after peer review.

- The final published version features the final layout of the paper including the volume, issue and page numbers.

Link to publication

\section{General rights}

Copyright and moral rights for the publications made accessible in the public portal are retained by the authors and/or other copyright owners and it is a condition of accessing publications that users recognise and abide by the legal requirements associated with these rights.

- Users may download and print one copy of any publication from the public portal for the purpose of private study or research.

- You may not further distribute the material or use it for any profit-making activity or commercial gain

- You may freely distribute the URL identifying the publication in the public portal.

If the publication is distributed under the terms of Article 25fa of the Dutch Copyright Act, indicated by the "Taverne" license above, please follow below link for the End User Agreement:

www.tue.nl/taverne

Take down policy

If you believe that this document breaches copyright please contact us at:

openaccess@tue.nl

providing details and we will investigate your claim. 


\title{
Analysis of Plasmonic Waveguides: An Embedding Approach
}

\author{
P.G. van Leuven * $\quad$ M.C. van Beurden ${ }^{\dagger} \quad$ A.G. Tijhuis ${ }^{\ddagger}$
}

\begin{abstract}
We present a hybrid modeling approach for the modeling of $2 \mathrm{D}$-waveguides in layered media based on an embedding envelope. The inner domain is treated spatially, and the outer domain is treated partly spatially for the direct terms, and partly spectrally for the reflected terms.
\end{abstract}

\section{INTRODUCTION}

At optical frequencies, metals are characterized by permittivities with a negative real part $\left(e^{j \omega t}\right.$ convention) and allow for guidance of waves confined to regions much smaller than the diffraction limit at the interface between the metal and the surrounding dielectric. These waves exhibit exponential decay in both the directions perpendicular to the interface. The main parameters for the guiding structure of such waves, i.e. the waveguide, are the propagation length and the confinement of the fields, which pose a fundamental trade-off. To increase confinement and lower the losses, many configurations have been studied in recent literature e.g. [1]. Typically these structures are embedded in a layered substrate, with metals like silver or gold.

\section{HYBRID MODELING APPROACH}

We present a hybrid modeling approach based on both spectral and spatial Green's functions, to solve the modal problem for such waveguides. The method relies on embedding the structure in a rectangular domain, the envelope (see Figure 1), and applying the Methods of Moments. The more complex structure in the inner domain, allows for a complete spatial treatment, and hence, is numerically tractable. For the outer region, the layered substrate, the Green's functions can be obtained in closed form in the spectral domain, e.g. following the Michalski $\mathrm{C}$ formulation [2]. The direct term

${ }^{*}$ Departement of Electrical Engineering, Eindhoven University of Technology Den Dolech 1, 5600MB Eindhoven, The Netherlands, e-mail: p.g.v.leuven@tue.nl, tel.: +31 (0)40 2473463.

${ }^{\dagger}$ Departement of Electrical Engineering, Eindhoven University of Technology Den Dolech 1, 5600MB Eindhoven, The Netherlands, e-mail: m.c.v.beurden@tue.nl.

${ }_{\ddagger}$ Departement of Electrical Engineering, Eindhoven University of Technology Den Dolech 1, 5600MB Eindhoven, The Netherlands, e-mail: a.g.tijhuis@tue.nl.

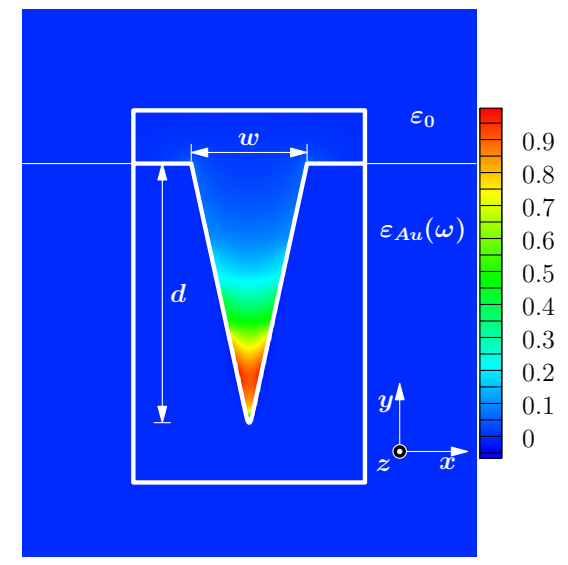

Figure 1: Normalized power density plot for $\operatorname{Re}\left\{S_{z}\right\}$ of a Channel Plasmon Polariton mode localized in the V-groove at $\lambda=750 \mathrm{~nm}$, with $w=$ $523 \mathrm{~nm}$ and $d=1.2 \mu \mathrm{m}$. The embedding envelope is shown by the thick white rectangle.

in the spectral domain is separated from the reflected terms, and allows for a spatial treatment, as the inverse Fourier transform exists in closed form. Furthermore, if the inner medium of the embedding rectangle is equal to that of the layer, this Green's function can be reused in the combination of the interior and exterior boundary integral equations.

The main numerical effort lies in the evaluation of the remaining reflected terms. Over the past decade several attempts have been made in lowering the numerical cost of this step, e.g. by using discrete complex imaging (DCIM) [3]. In our approach, however, the rectangular shape of the envelope fits the spectral domain naturally, which has three major advantages. First, the implementation is less complicated compared to the DCIM approach. Second, the kernels in the inverse Fourier transform can be separated in functions of $x$ and $y$, which in turn makes it possible to separate even and odd terms with respect to the spectral transform variable $k_{x}$. By doing so, the inverse Fourier integral reduces to an integral from 0 to $\infty$, and requires half the numerical effort. Furthermore, the surface-wave poles are accounted for by adding their residues if needed, such that the integration path can be chosen conveniently. The residues need to be calculated only once for each observation and 
source layer combination. Hence, the numerical effort in calculating these is not significant. Third, the geometrical properties of the rectangle may be exploited. After a uniform segmentation is applied to the envelope, many of the integrals over the test and expansion segments can be reused. This effectively lowers the numerical cost by a factor of about 5 to 10 , depending on the aspect ratio of the rectangle.

The modes are then found by using a search algorithm based on the argument principle in combination with a Newton search, applied to the determinant of the MoM matrix.

\section{RESULTS}

As an example of a plasmonic waveguide, we analyze the $\mathrm{V}$-grooved structure presented in Figure 1 with our proposed modeling method. This type of structure has been thoroughly studied (e.g. in [1] and [4]) and supports a Channel Plasmon Polariton (CPP) mode. We assume a field dependency of $e^{-\gamma_{z} z}$, where $\gamma_{z}=\alpha_{z}+j \beta_{z}$ is the complex propagation constant. We use the Drude-Lorentz model presented in [5] for the gold lower half-space. The upper half space is assumed to be vacuum. The embedding envelope crosses the layer interface. Figure 1 also shows the normalized power density flowing in the $z$-direction (i.e. $\operatorname{Re}\left\{S_{z}\right\}$ ), from which the confinement of the fields can be clearly observed. In Figure 2 the dispersion effect is shown for the Vgroove waveguide. The figure also shows the propagation length, $L_{p}=\left(2 \alpha_{z}\right)^{-1}$. The two quantities demonstrate the fundamental trade-off between propagation length and confinement. As the wavelength decreases, the modal energy becomes more localized in the tip of the $\mathrm{V}$-groove, whereas the propagation length decreases. Conversely, as the wavelength increases, the modal energy localizes in the gap leading to low confinement, but exhibits longer propagation lengths. The results are close to the results that have been published in [4].

\section{CONCLUSIONS}

We have developed a numerical model for the analysis of waveguides, where the guiding structure of a waveguide is embedded in a rectangular domain. The validity of the model has been shown by the analysis of a typical V-groove plasmonic waveguide.

\section{ACKNOWLEDGEMENTS}

The authors would like to thank Lorenzo Tripodi and Marion Matters from Philips Research as well as Jaime Gomez-Rivas and Audrey Berrier from

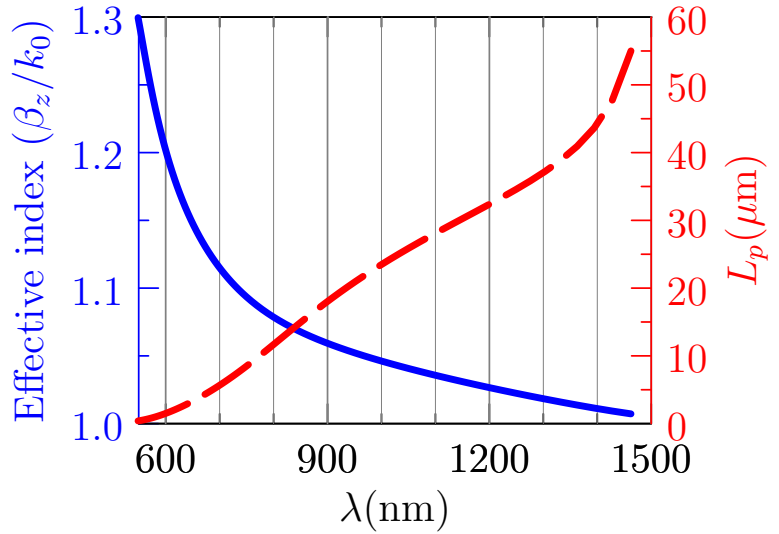

Figure 2: The solid line shows the effective index (left vertical axis), for the $\mathrm{V}$-groove CPP-mode. The dashed line shows the propagation length $L_{p}$ for this type of structure (right vertical axis).

AMOLF for useful discussions. This research is funded by Philips Research.

\section{References}

[1] R. Oulton, G. Bartal, D. Pile, and X. Zhang, "Confinement and propagation characteristics of subwavelength plasmonic modes," New Journal of Physics, vol. 10, p. 105018, 2008.

[2] K. Michalski and D. Zheng, "Electromagnetic scattering and radiation by surfaces of arbitraryshape in layered media. I. Theory," IEEE Transactions on Antennas and propagation, vol. 38, no. 3, pp. 335-344, 1990.

[3] J. Bernal, F. Medina, and R. Boix, "Full-wave analysis of nonplanar transmission lines on layered medium by means of MPIE and complex image theory," IEEE Transactions on $\mathrm{Mi}$ crowave Theory and Techniques, vol. 49, no. 1, pp. 177-185, 2001.

[4] I. Lee, J. Jung, J. Park, H. Kim, and B. Lee, "Dispersion characteristics of channel plasmon polariton waveguides with step-trenchtype grooves," Opt. Express, vol. 15, no. 25, pp. 16 596-16 603, 2007.

[5] A. Vial, A. Grimault, D. Macías, D. Barchiesi, and M. de La Chapelle, "Improved analytical fit of gold dispersion: Application to the modeling of extinction spectra with a finitedifference time-domain method," Physical Review $B$, vol. 71, no. 8, p. 85416, 2005. 